\title{
Using the health belief model to assess beliefs and behaviors regarding cervical cancer screening among Saudi women: a cross-sectional observational study
}

\author{
Arwa I. Aldohaian * (D), Sulaiman A. Alshammari and Danyah M. Arafah
}

\begin{abstract}
Background: Cervical cancer in Saudi Arabia is ranked as the third most frequent gynecological cancer among women. The Pap smear test is a screening test that can be used as a primary prevention tool for cervical cancer, and prophylactic vaccination against HPV is also considered to be a factor in decreasing the prevalence of the disease. This study aimed to assess women's beliefs about cervical cancer and the Pap smear test. In addition, the relationship between cervical cancer and the social and demographic characteristics was also evaluated.

Methods: A descriptive cross-sectional study was performed among Saudi women living in Riyadh in 2018. Women were randomly selected, and the total sample size was 450. A predesigned self-administered questionnaire that included the Health Belief Model scale was used to collect data. Data were analyzed using SPSS 21.0. $P$ values $<0.05$ were considered as statistically significant in this study.

Results: Among the 450 participants, the Pap smear test uptake was 26\% and the HPV vaccine uptake was less than $1 \%$. A low education level and family history for cervical cancer were significantly associated with the belief of high susceptibility for developing cervical cancer $(p<0.05)$. The seriousness of the disease was recognized by $38 \%$, and the benefit of screening was recognized by $82 \%$ of the participants. In addition, $27 \%$ of the participants perceived barriers to obtaining a Pap smear test.

Conclusions: This study showed a high level of perception regarding benefits and motivation, and a low incidence of perceived barriers among women regarding cervical cancer screening. However, these attitudinal aspects did not translate into practice, as reflected by the low uptake of the screening test. Our findings imply that concerted efforts are needed to promote cervical cancer screening programs in Saudi Arabia. In view of the planned implementation of Saudi vision 2030, which emphasizes on prevention, we recommend launching a national cervical cancer screening program, to be available and accessible to all women in primary health care centers and hospitals.
\end{abstract}

Keywords: Cervical cancer screening, Health belief model, HPV vaccine

\footnotetext{
* Correspondence: arwaksu2009@gmail.com

Department of Family \& community medicine, College of Medicine, King

Saud Medical University, Riyadh, Kingdom of Saudi Arabia
}

(c) The Author(s). 2019 Open Access This article is distributed under the terms of the Creative Commons Attribution 4.0 International License (http://creativecommons.org/licenses/by/4.0/), which permits unrestricted use, distribution, and reproduction in any medium, provided you give appropriate credit to the original author(s) and the source, provide a link to the Creative Commons license, and indicate if changes were made. The Creative Commons Public Domain Dedication waiver (http://creativecommons.org/publicdomain/zero/1.0/) applies to the data made available in this article, unless otherwise stated. 


\section{Background}

Cervical cancer is a preventable disease. It is the fourth most common cancer among women globally. The estimated number of cervical cancer cases in the world is 528,000 per year. This cancer type is also considered to be the second most common cancer in developing countries with over 400,000 cases reported yearly. Cervical cancer is the third cause of cancer-related death in developing countries (230,158 deaths per year) [1]. This means that $80 \%$ or more of the global burden of cervical cancer occurs in developing countries [2]. The explanation behind the higher mortality of cervical cancer in developing countries is that in these countries, the spending on cancer prevention programs is only approximately $5 \%$ of that spent by developed countries worldwide [3].

In Saudi Arabia, cervical cancer is the third most common gynecological malignancy in Saudi women. The incidence rate of new cases of cervical cancer was 1.9 per 100,000 in 2014 [4]. The estimated number of new cervical cancer cases and the number of deaths per year was 152 and 55, respectively [5]. However, more than $40 \%$ of women having cervical cancer are diagnosed at advanced stages in Saudi Arabia, compared to $25 \%$ in British Columbia, Canada. This high prevalence of delay in diagnosis is probably due to the lack of effective prevention and screening programs in Saudi Arabia $[5,6]$.

Studies have recognized a strong association between cervical cancer and human papillomavirus (HPV) serotypes 16 and 18 [7]. Almost 70\% of cervical cases are caused by HPV 16 and 18 [8]. This virus affects changes in the cervical epithelium metaplasia, and such changes usually occur more rapidly during puberty [7]. The Advisory Committee on Immunization Practices in the United States of America (USA) has recommended routine HPV vaccination for girls at the age of 11 or 12 years. Vaccination may be performed at any time until the age of 26 years for those who have not been vaccinated previously or have not finished the three-dose series [9].

There are many risk factors for cervical cancer, and include the following: sexual activity at younger than 21 years of age (1.5-fold increase in risk compared to that for sexual activity initiated from 18 to 20 years of age and 2-fold increase for that initiated at less than 18 years of age), having multiple sexual partners, use of hormonal contraceptives for more than 5 years, increasing parity (three or more full-term pregnancies), smoking, and a history of sexually transmitted infections $[10,11]$. The primary goal of cervical cancer prevention is to reduce the incidence by addressing the causes and the risk factors [12].

The cervical cancer screening test allows for early detection of cervical cancer. Pap smear screening, which identifies cytological abnormalities of the cervical transformation zone, has helped to reduce the incidence and mortality rates of cervical cancer by $70 \%$ in developed countries within 3 years after implementation of screening programs [13-15]. It is well known that cancer develops 10 years or more after the development of detectable precancerous lesions. Women between 30 and 40 years of age are at a higher risk of precancerous lesions [16].

Accordingly, the Saudi guideline for cervical cancer screening recommends that the universal screening strategy be followed [5]. The United States Preventive Services Task Force has recommended a Pap smear test every 3 years for women aged between 21 and 65 years. For women aged between 30 and 65 years who want to increase the length of the screening interval, a Pap smear test combined with a HPV test conducted every 5 years is recommended [17].

Unfortunately, many women remain asymptomatic until the disease has advanced, especially those women who are not sexually active. The presenting early symptoms of invasive cervical cancer are vaginal discharge, irregular bleeding, postcoital spotting, and pre- or postmenopausal spotting or bleeding. Furthermore, more advanced symptoms are urinary frequency and urgency, lower abdominal pain, severe back pain, and weight loss [18].

It is essential to study the risk factors for cervical cancer among women as well as the emotional, cognitive, and environmental aspects, which influence the women's decision to participate in screening programs. The Health Belief Model (HBM) focuses on a person's health-related behavior for predicting future actions [19]. The HBM has been tested, translated, and used to study women in different cultures [20].

According to this model, the decision to participate in programs designed to prevent or detect disease is determined by many factors: perceived susceptibility to the health condition, awareness of the impact of disease on their health (perceived severity), perceived benefits of undergoing screening, and perceived barriers and costs of the screening methods $[19,21]$.

To date, there have been no studies employing the HBM with regard to cervical cancer in Saudi Arabia. Therefore, the aim of this study is to 1) assess women's beliefs toward cervical cancer and the Pap smear test in Riyadh, and 2) to assess women's knowledge and beliefs regarding cervical cancer and the Pap smear test in relation to socio-demographic characteristics. The results of this study may provide a baseline assessment for future intervention programs to promote early detection and early management of cervical cancer.

\section{Methods}

Study design and setting

A cross-sectional study was conducted in all women who attended the gynecology outpatient clinics in 
Riyadh's four main hospitals (King Khaled University, Alyamamah, King Saud Hospital, and the King Fahad Medical City) and primary care centers in Riyadh that were randomly selected by sectors as defined by the ministry of sectoral health division. Two primary care centers from each sector (North, South, Center, East, and West) were selected (for a total of 10 primary care centers).

\section{Sample size}

We used the electronic sample size calculator, the openEpi software, to determine the required sample size. The equation used for this calculation is given below:

$\mathrm{n}=\left[\operatorname{DEFF}^{*} \mathrm{~Np}(1-\mathrm{p})\right] /\left[\left(\mathrm{d} 2 / \mathrm{Z} 21-\alpha / 2^{*}(\mathrm{~N}-1)+\mathrm{p}^{*}(1-\mathrm{p})\right]\right.$

$\mathrm{n}=$ required sample size

$(\mathrm{N}$ : Population size(for finite population correction factor or fpc) (1000000))

(p: Hypothesized \% frequency of outcome factor in the population $(50 \% \pm 5))$

(d: Confidence limits as \% of 100 (absolute $\pm 5 \%)$ )

Design effect (for cluster surveys-DEFF): 1

$\mathrm{z}=$ confidence level at 95\% (standard value of 1.96)

$\mathrm{m}=$ margins of error at $5 \%$ (standard value of 0.05 )

sample size $=385$; the expected non-response rate was set at $20 \%$

Total sample size: 450

\section{Sampling technique and study subjects}

The investigator collected the data from January 15, 2018 to February 30, 2018. Participants were selected randomly as follows: 150 women from the King Khalid University Hospital, 150 from the Ministry of Health Hospitals (50 from each hospital), and 150 from primary care centers (30 from each sector).

The inclusion criteria were: Saudi women (1), aged 18 years or older (2) not diagnosed with gynecological cancer, and (3) agreed to participate in the study.

\section{Data collection}

A predesigned self-administered questionnaire was composed according to the findings from three validated published studies that were conducted in Turkey, Egypt, and Alahsa (Saudi Arabia). Furthermore, CHBM components were added to the questionnaire after obtaining permission from the copyright owner $[19,22,23]$. This self-administered questionnaire includes questions about the following topics: (1) socio-demographic characteristics; (2) knowledge about cervical cancer and about the Pap smear test; (3) HPV)-related questions; and the (4) HBM scale for cervical cancer and for the Pap smear test. The following section describes the various parts included the in the questionnaire and the topics covered in each part:

\section{Part I}

Socio-demographic characteristics such as age, area of residence, educational status, working status, marital status, age at marriage, duration of marriage, number of living children, usage of hormonal contraception, smoking, and family history of cervical cancer.

\section{Part 2}

Knowledge about cervical cancer and about the Pap smear test (yes, no, and I do not know options for being familiar with the Pap smear test; the source of information about the Pap smear test; knowledge about the Pap smear test being the main cervical cancer screening test; knowledge that cervical cancer is the most frequent cancer among women; yes and no options for whether the participant had undergone a Pap smear test; knowledge about the appropriate age at which women require a Pap smear test). Possible signs of cervical cancer were queried in 10 items (weight loss, blood in the stool or urine, vaginal bleeding after the menopause or after having sexual intercourse, pain during sexual intercourse, heavy of prolonged menstrual periods, persistent vaginal bleeding or discharge, pelvic pain and lower back pain) with "yes", "no", and "I do not know" options. Correct responses for possible signs were assigned a score of one point while the responses "No" or "I do not know" were assigned zero points.

The possible risk factors of cervical cancer were queried using 8 items (HPV status, smoking, weakened immunity, use of contraceptive pills, history of Chlamydia infections, marriage at a younger age, having many children, and not undergoing Pap smear tests regularly) using 5-point Likert-type scale options (strongly disagree (1 point) to strongly agree (5 points)). One item was removed from the original form from the risk factors section (having many sexual partners), since it is a sensitive question in view of the conservative nature of the Saudi society.

\section{Part 3}

Assessing the uptake of HPV vaccination with "yes," "no," and "I do not know" options. The reasons for not obtaining the vaccination and age of vaccination were also queried. The internal consistency measure (Cronbach's alpha) of the modified instrument was 0.784 for knowledge of cervical cancer and the HPV vaccine (all items), 0.86 for the signs and symptoms section (10 items), and 0.69 for the risk factors section (eight items), as revealed by pilot testing. 


\section{Part 4}

Using the HBM scale for cervical cancer and the Pap smear test. The scale was used based on Victoria Champion CHBM scale. The format, content, and validity of scale were tested and used in different language and culture. Permission was obtained from Champion to adapt the scale and to make the necessary changes to render them in order to be valid for both Arabic language and culture. This scale has five subscales: Perceived susceptibility to having disease was assessed by using three items "It is likely that I will get cervical cancer in the future", "My chances of getting cervical cancer in the next few years are high", and "I feel I will get cervical cancer sometime during my life."; perceived seriousness of cervical cancer was assessed by seven items, e.g., " Problems I would experience with cervical cancer would last a long time." Perceived benefits of undergoing a Pap smear test were assessed by eight items, e.g., "Having regular Pap smear Tests will help to detect changes to the cervix before they turn into cancer." Perceived motivation toward improving health was assessed using three items, e.g., "I eat well-balanced meals for my health." Perceived Pap smear test barriers were evaluated using 18 items, e.g., "I am afraid to have a Pap smear Test for fear of a bad result." All items of the subscales have the following five-point Likert-type response choices: strongly disagree (1 point), disagree ( 2 points), neutral ( 3 points), agree ( 4 points), and strongly agree ( 5 points). Each of the subscales was assessed separately, and the total score was not calculated. Subscale scores were calculated for each participant. Higher scores indicate stronger feelings about that construct. All subscales had positive responses related to the screening behavior, except for barriers which are negatively associated. In the original test, Cronbach's alpha coefficients for the five subscales were observed to fall between 0.62 and 0.86 . In this study, Cronbach's alpha coefficients of 0.89 were observed for the five subscales.

The English questionnaires were translated by two language experts into Arabic and were back-translated to English by two different independent language experts according to Beaton-recommended guidelines [24]. This questionnaire was reviewed by two family physicians, two gynecologists, and one community professor. All the above reviewers are academic experts in their respective fields.

\section{Pilot study}

Prior to the main study, the author conducted a pilot study with the questionnaire in 40 women to check the applicability and clarity, and to identify any difficulties with the questionnaire; the pilot study was also employed to ensure the cultural and scientific appropriateness of the instrument for the Saudi community, as well as to estimate the time needed to fill out the questionnaire. The questionnaires take approximately 15-20 min to fill out. Modification of the questionnaire was performed according to the results of the pilot study. Women who participated in the pilot study were excluded from the main study.

\section{Data management}

Data were analyzed using the SPSS 21.0 software (SPSS Inc., IBM, USA). The socio-demographic characteristics and knowledge of cervical cancer in participating women are reported as mean, median, number, and percentage distribution, as appropriate. The average score on the HBM Scale for cervical cancer and that for the Pap test (reported as numbers, percentage, and median) were analyzed by parametric (independent sample t-test) and non-parametric tests (Kruskal Wallis test). Correlation analysis (analysis of variance test) was used to determine the relationship between socio-demographic characteristics, knowledge of cervical cancer, and the HBM scale for cervical cancer and the Pap smear test. $P$ values < 0.05 were accepted as statistically significant.

\section{Results}

Four hundred and fifty women participated in the present study. Table 1 shows that all participants in the study lived in Riyadh city. The mean age of the study participants was $32.9 \pm 8.3$ years. Majority of the participants $(306 ; 68 \%)$ had a university level or higher education status. A little over half of the participants were not employed $(244 ; 54 \%)$. The majority of participants were married (366; 81\%), while the rest were unmarried (84; $19 \%)$. The mean age at marriage was $23.1 \pm 4.4$ years. The mean duration of marriage was $10.3 \pm 8.4$ years. Roughly one-third of the participants $(144 ; 32 \%)$ had two or three children.

Table 2 shows that older women believed that it is beneficial to have a Pap smear test, while women who had a low education level believed they were more susceptible to developing cervical cancer. Women who were working had more knowledge about the signs of cervical cancer. Women who had a long marriage duration were more motivated to promote self-health than did others. Women who had more children believed they were more susceptible to developing cervical cancer. Non-smoking women perceived a benefit in undergoing a cervical cancer screening test. Additionally, women who were socially interactive with health professionals, family, and friends were more aware about the Pap smear test barriers than were women who obtained their information from the media. Women who had a positive family history of cervical cancer believed they were more susceptible to developing cervical cancer. 
Table 1 Socio-demographic data of participants $(n=450)$

\begin{tabular}{|c|c|c|}
\hline & Number & Percent \\
\hline \multicolumn{3}{|l|}{ Age } \\
\hline Mean \pm SD & $32.9 \pm 8.3$ & \\
\hline Range (Min. - Max.) & $18-57$ & \\
\hline \multicolumn{3}{|l|}{ Level of education } \\
\hline Primary + Read \& write & 10 & 2 \\
\hline Intermediate school & 19 & 4 \\
\hline High school & 115 & 26 \\
\hline University or higher & 306 & 68 \\
\hline \multicolumn{3}{|l|}{ Employment status } \\
\hline Working & 206 & 46 \\
\hline Not working & 244 & 54 \\
\hline \multicolumn{3}{|l|}{ Marital status } \\
\hline Married & 366 & 81 \\
\hline Unmarried $^{a}$ & 84 & 19 \\
\hline Single & 58 & 13 \\
\hline Divorced & 22 & 5 \\
\hline Widow & 4 & 1 \\
\hline \multicolumn{3}{|l|}{ Age at marriage } \\
\hline 18 to 29 years & 325 (82.9\%) & 83 \\
\hline Mean \pm SD & $23.1 \pm 4.4$ & \\
\hline Range (Min. - Max.) & $12.0-38.0$ & \\
\hline \multicolumn{3}{|l|}{ Marriage period } \\
\hline Mean \pm SD & $10.3 \pm 8.4$ & \\
\hline Range (Min. - Max.) & $0.08-37$ & \\
\hline \multicolumn{3}{|l|}{ Number of children } \\
\hline None & 128 & 28 \\
\hline One child & 83 & 19 \\
\hline $2-3$ children & 144 & 32 \\
\hline 4-5 children & 58 & 13 \\
\hline 6 or more children & 37 & 8 \\
\hline
\end{tabular}

$S D$ standard deviation, Min minimum, Max maximum, ${ }^{a}$ include (Single, Divorced, Widow)

Table 3 shows that almost half of the participants (48.7\%) had knowledge about the Pap smear test. The most popular sources of relevant information were health professionals $(59.8 \%)$, followed by the media (23.7\%). More than two-thirds $(74 \%)$ of the participants had not undergone a Pap smear screening test. The mean age for undergoing a Pap smear screening test was $31.8 \pm 7.8$ years. A majority of the participants (192; $42.6 \%)$ selected the age range of 30-40 years, while 149 (33.1\%) participants did not know the proper age for undergoing Pap smear screening.

Table 4 shows that the majority of participants (424; 94.2\%) did not receive the HPV vaccine, and that less than $1 \%$ had been vaccinated (the rest did not know their vaccination status). The most popular reason for not receiving the vaccination was lack of knowledge about the vaccine $(91.1 \%)$, while less than one-tenth of the participants (6.4\%) cited other reasons such as fear of infection and refusal from parents or husband due to high cost. Majority of the participants did not know the appropriate age to receive the vaccination $(258 ; 57.3 \%)$; the mean age for HPV vaccination among those who were vaccinated was $29.9 \pm 8.6$ years.

Table 5 shows a comparison of HBM parameters with respect to different health institutions. We found no difference among participants with regard to HBM parameters pertaining to cervical cancer except for the parameter "benefits" which showed statistically significant differences among types of health institutions.

Table 6 shows that $12 \%$ of the participants considered themselves to be at risk of developing cervical cancer (perceived susceptibility). Additionally, over $36 \%$ of the participants agreed to the statements related to the seriousness of the disease. Regarding perceived benefits of the Pap smear test, approximately $82 \%$ of the participants believed that undergoing regular Pap smear tests would help to find changes to the cervix before cancer develops, that regular Pap smear tests are the best way to diagnose cervical cancer at an early stage, and that cervical cancer treatment would be tolerable. In addition, almost $70 \%$ of women were motivated to promote their health (health motivation measures). Twenty-seven percent of the participants had experienced barriers to obtaining a Pap smear test. For example, $79 \%$ of participants preferred a female doctor rather than a male doctor, $40.5 \%$ of participants would feel embarrassed to lie on a gynecologic examination couch, $38 \%$ of women believed that they neglect or forget to undergo regular Pap smear tests. Additionally, $52 \%$ of the participants did not know where to go for a Pap smear test, and $42 \%$ believed that "if there is cervical cancer development in my destiny, having a Pap smear test cannot prevent it." Furthermore, other perceived barriers included a belief that the Pap smear test takes a long time to administer (11.7\%), the cost of the test is high $(21.6 \%)$, lack of time to schedule a test (15\%), bad manners of health professionals (12.2\%), and that the procedure may be painful (21\%). With regard to pain, out of 101 of women who had undergone a Pap smear test, only $29(28.7 \%)$ women found it painful. In comparison, 54 (18\%) out of 291 married women who did not undergo the test perceived that the Pap smear test involves a painful procedure.

\section{Discussion}

This study focused on assessing health beliefs regarding cervical cancer and the Pap smear test among Saudi women living in Riyadh, and evaluated the association 
Table 2 Relationship between socio-demographic characteristics, knowledge, and HBM scale for cervical cancer and the pap test

\begin{tabular}{|c|c|c|c|c|c|c|c|c|}
\hline \multirow[t]{2}{*}{$\begin{array}{l}\text { Socio-demographic } \\
\text { characteristics }\end{array}$} & $N$ & $\begin{array}{l}\text { Knowledge about } \\
\text { sing of CC }(n=450)\end{array}$ & $\begin{array}{l}\text { Knowledge about } \\
\text { risk factors }(n=450)\end{array}$ & $\begin{array}{l}\text { Susceptibility } \\
(n=450)\end{array}$ & $\begin{array}{l}\text { Seriousness } \\
(n=450)\end{array}$ & $\begin{array}{l}\text { Benefits } \\
(n=450)\end{array}$ & $\begin{array}{l}\text { Health Motivation } \\
(n=450)\end{array}$ & $\begin{array}{l}\text { Barriers } \\
(n=450)\end{array}$ \\
\hline & Total & $\begin{array}{l}\text { Median } \\
\text { (Min. - Max.) }\end{array}$ & $\begin{array}{l}\text { Median } \\
\text { (Min. - Max.) }\end{array}$ & $\begin{array}{l}\text { Median } \\
\text { (Min. - Max.) }\end{array}$ & $\begin{array}{l}\text { Median } \\
\text { (Min. - Max.) }\end{array}$ & $\begin{array}{l}\text { Median } \\
\text { (Min. - Max.) }\end{array}$ & $\begin{array}{l}\text { Median } \\
\text { (Min. - Max.) }\end{array}$ & $\begin{array}{l}\text { Median } \\
\text { (Min. - Max.) }\end{array}$ \\
\hline \multicolumn{9}{|l|}{$\overline{\text { Age }}$} \\
\hline$\leq 20$ years & 16 & $2(0-5)$ & $19.5(16-26)$ & $7.5(3-14)$ & $20.5(8-34)$ & $34.5(25-40)$ & $11(5-14)$ & $54(41-73)$ \\
\hline $21-30$ years & 198 & $3(0-10)$ & $21(8-40)$ & $7(3-14)$ & $21(7-34)$ & $35(8-40)$ & $12(3-15)$ & $51(18-74)$ \\
\hline $31-40$ years & 162 & $3(0-10)$ & $20(8-40)$ & $8(3-15)$ & $22(7-35)$ & $34(8-40)$ & $12(3-15)$ & $54(18-85)$ \\
\hline$>40$ years & 74 & $2.5(0-10)$ & $21(8-31)$ & $8(3-15)$ & $21.5(8-35)$ & $36(26-40)$ & $12(6-15)$ & $51.5(28-72)$ \\
\hline$P$-value & 450 & 0.550 & 0.887 & 0.467 & 0.479 & 0.047 & 0.069 & 0.128 \\
\hline \multicolumn{9}{|l|}{ Education levels } \\
\hline Primary school & 10 & $0.5(0-7)$ & $21(16-35)$ & $9(7-14)$ & $25(15-33)$ & $37.5(28-40)$ & $12(6-15)$ & $55.5(34-72)$ \\
\hline $\begin{array}{l}\text { Intermediate } \\
\text { school }\end{array}$ & 19 & $1(0-6)$ & $20(14-24)$ & $9(3-13)$ & $23(8-34)$ & $36(22-40)$ & $12(3-15)$ & $57(33-72)$ \\
\hline High school & 115 & $2(0-9)$ & $20(8-34)$ & $7(3-15)$ & $22(7-35)$ & $35(8-40)$ & $12(3-15)$ & $51(18-85)$ \\
\hline $\begin{array}{l}\text { University or } \\
\text { higher }\end{array}$ & 306 & $3(0-10)$ & $21(8-40)$ & $7(3-15)$ & $21(7-35)$ & $35(8-40)$ & $12(3-15)$ & $52(18-80)$ \\
\hline$P$-value & 450 & 0.029 & 0.075 & 0.010 & 0.126 & 0.359 & 0.483 & 0.125 \\
\hline \multicolumn{9}{|l|}{ Employment status } \\
\hline Working & 206 & $3(0-10)$ & $21(8-40)$ & $7.0(3-15)$ & $21(7-35)$ & $34.5(9-40)$ & $12(3-15)$ & $52(20-81)$ \\
\hline Not working & 244 & $2(0-9)$ & $20(8-40)$ & $7.0(3-15)$ & $21(7-35)$ & $35(8-40)$ & $12(3-15)$ & $52(18-85)$ \\
\hline$P$-value & 450 & 0.001 & 0.675 & 0.224 & 0.857 & 0.169 & 0.783 & 0.831 \\
\hline \multicolumn{9}{|l|}{ Marital status } \\
\hline Single & 58 & $2.5(0-9)$ & $21(14-40)$ & $7(6-15)$ & $21.5(8-35)$ & $35(8-40)$ & $12(3-15)$ & $56(35-90)$ \\
\hline Married & 366 & $3(0-10)$ & $20(8-40)$ & $7(3-15)$ & $21(7-35)$ & $35(8-40)$ & $12(3-15)$ & $56(23-90)$ \\
\hline Divorce & 22 & $1(0-9)$ & $23(8-27)$ & $8.5(3-15)$ & $21(7-27)$ & $34.5(8-40)$ & $11(3-15)$ & $54.5(37-73)$ \\
\hline Widow & 4 & $1(0-4)$ & $22.5(15-30)$ & $6(9-15)$ & $19(16-21)$ & $34.5(10-40)$ & $10.5(5-15)$ & $52.5(44-54)$ \\
\hline$P$-value & 450 & 0.317 & 0.219 & 0.498 & 0.568 & 0.868 & 0.326 & 0.610 \\
\hline \multicolumn{9}{|l|}{ Age when married } \\
\hline Less than 18 years & 33 & $4(0-10)$ & $20(8-26)$ & $8(3-14)$ & $20(7-34)$ & $36(8-40)$ & $12(3-12)$ & $58(36-70)$ \\
\hline 18-29 years & 325 & $3(0-10)$ & $21(8-40)$ & $7(3-15)$ & $21(7-35)$ & $35(8-40)$ & $12(3-15)$ & $56(27-90)$ \\
\hline $30-40$ years & 34 & $1(0-9)$ & $23(12-35)$ & $7(6-15)$ & $22.5(7-35)$ & $33.5(8-40)$ & $12(3-15)$ & $58(23-86)$ \\
\hline$P$-value & 392 & 0.708 & 0.056 & 0.057 & 0.422 & 0.052 & 0.977 & 0.792 \\
\hline \multicolumn{9}{|l|}{ Marriage period } \\
\hline 1 month -5 years & 135 & $2(0-10)$ & $21(8-40)$ & $7(3-15)$ & $20(7-35)$ & $34(17-40)$ & $11(5-15)$ & $53(21-85)$ \\
\hline$>5-10$ years & 108 & $3(0-10)$ & $20(11-40)$ & $8(3-14)$ & $21(7-35)$ & $35(8-40)$ & $12(3-15)$ & $51(18-77)$ \\
\hline$>10$ years & 149 & $3(0-10)$ & $20(8-33)$ & $7.6(3-15)$ & $22.5(7-35)$ & $35(19-40)$ & $12(5-15)$ & $52(20-81)$ \\
\hline$P$-value & 392 & 0.703 & 0.378 & 0.148 & 0.387 & 0.055 & 0.005 & 0.626 \\
\hline \multicolumn{9}{|l|}{ Number of children } \\
\hline None & 128 & $2(0-10)$ & $21(8-40)$ & $7(3-15)$ & $22(7-35)$ & $34(8-40)$ & $12(3-15)$ & $55(23-90)$ \\
\hline One child & 83 & $1(0-10)$ & $21(12-40)$ & $7(3-15)$ & $22(7-35)$ & $34(8-40)$ & $11(3-13)$ & $57(37-88)$ \\
\hline 2 or 3 children & 144 & $3(0-10)$ & $20(8-40)$ & $8(3-15)$ & $21(7-35)$ & $35(8-40)$ & $12(3-15)$ & $57(28-90)$ \\
\hline 4 children or more & 95 & $3(0-10)$ & $19.7(8-33)$ & $8(3-15)$ & $19.2(9-35)$ & $35.7(8-40)$ & $12(3-15)$ & $57(27-72)$ \\
\hline$p$-value & 450 & 0.273 & 0.041 & 0.016 & 0.237 & 0.077 & 0.058 & 0.142 \\
\hline \multicolumn{9}{|l|}{ Use contraceptive } \\
\hline Yes & 110 & $3(0-10)$ & $20(8-40)$ & $8(3-15)$ & $21(7-35)$ & $35(8-40)$ & $12(3-15)$ & $57(27-78)$ \\
\hline No & 340 & $2(0-10)$ & $21(8-40)$ & $7(3-15)$ & $21(7-35)$ & $35(8-40)$ & $12(3-15)$ & $55(23-90)$ \\
\hline
\end{tabular}


Table 2 Relationship between socio-demographic characteristics, knowledge, and HBM scale for cervical cancer and the pap test (Continued)

\begin{tabular}{|c|c|c|c|c|c|c|c|c|}
\hline \multirow[t]{2}{*}{$\begin{array}{l}\text { Socio-demographic } \\
\text { characteristics }\end{array}$} & N & $\begin{array}{l}\text { Knowledge about } \\
\text { sing of CC }(n=450)\end{array}$ & $\begin{array}{l}\text { Knowledge about } \\
\text { risk factors }(n=450)\end{array}$ & \multirow{2}{*}{$\begin{array}{l}\text { Susceptibility } \\
(n=450) \\
\text { Median } \\
\text { (Min. - Max.) }\end{array}$} & \multirow{2}{*}{$\begin{array}{l}\text { Seriousness } \\
(n=450) \\
\text { Median } \\
\text { (Min. - Max.) }\end{array}$} & \multirow{2}{*}{$\begin{array}{l}\text { Benefits } \\
(n=450) \\
\text { Median } \\
\text { (Min. - Max.) }\end{array}$} & \multirow{2}{*}{$\begin{array}{l}\text { Health Motivation } \\
(n=450) \\
\text { Median } \\
\text { (Min. - Max.) }\end{array}$} & \multirow{2}{*}{$\begin{array}{l}\text { Barriers } \\
(n=450) \\
\text { Median } \\
\text { (Min. - Max. }\end{array}$} \\
\hline & Total & $\begin{array}{l}\text { Median } \\
\text { (Min. - Max.) }\end{array}$ & $\begin{array}{l}\text { Median } \\
\text { (Min. - Max.) }\end{array}$ & & & & & \\
\hline P-value & 450 & 0.383 & 0.573 & 0.629 & 0.912 & 0.425 & 0.156 & 0.481 \\
\hline \multicolumn{9}{|l|}{ Smoking } \\
\hline Yes & 12 & $4(0-6)$ & $23.5(17-28)$ & $9(8-15)$ & $15.5(12-31)$ & $31.5(9-40)$ & $11.5(3-15)$ & $54(46-88)$ \\
\hline No & 438 & $3(0-10)$ & $21(8-40)$ & $7(3-15)$ & $21(7-35)$ & $35(8-40)$ & $12(3-15)$ & $56(23-90)$ \\
\hline$P$-value & 450 & 0.947 & 0.237 & 0.488 & 0.538 & 0.027 & 0.129 & 0.744 \\
\hline \multicolumn{9}{|c|}{ Whether she had information about the Pap test? } \\
\hline Yes & 219 & $3(0-10)$ & $21(8-40)$ & $7(3-15)$ & $21(7-34)$ & $35(8-40)$ & $12(3-15)$ & $49(18-81)$ \\
\hline No & 231 & $2(0-10)$ & $21(8-40)$ & $8(3-15)$ & $21(7-35)$ & $35(8-40)$ & $12(3-15)$ & $54(18-85)$ \\
\hline$P$-value & 450 & 0.001 & 0.906 & 0.593 & 0.887 & 0.858 & 0.217 & $P<0.0001$ \\
\hline \multicolumn{9}{|c|}{ Source of the information about the Pap test is: } \\
\hline $\begin{array}{l}\text { Health } \\
\text { professional }\end{array}$ & 121 & $3(0-10)$ & $21(8-30)$ & $7(3-13)$ & $21(7-34)$ & $35(8-40)$ & $11(3-15)$ & $48(18-81)$ \\
\hline Family & 17 & $5(0-10)$ & $18(13-30)$ & $7(3-12)$ & $20(7-27)$ & $35(9-40)$ & $12(3-15)$ & $42(27-58)$ \\
\hline Media & 62 & $3(0-9)$ & $21(13-40)$ & $7(3-13)$ & $21(10-32)$ & $35(24-40)$ & $12(5-15)$ & $52(37-65)$ \\
\hline Other & 19 & $4(0-9)$ & $22(14-28)$ & $8(3-15)$ & $22(7-33)$ & $36(23-40)$ & $12(7-15)$ & $51(21-65)$ \\
\hline P-value & 219 & 0.096 & 0.061 & 0.897 & 0.658 & 0.900 & 0.265 & 0.005 \\
\hline \multicolumn{9}{|c|}{ Family history cervical cancer } \\
\hline Yes & 22 & $2(0-8)$ & $22(8-30)$ & $9(4-15)$ & $23.5(7-35)$ & $35(9-40)$ & $11.5(3-15)$ & $54(40-69)$ \\
\hline No & 400 & $3(0-10)$ & $21(8-40)$ & $7(3-15)$ & $21(7-35)$ & $35(8-40)$ & $12(3-15)$ & $52(18-85)$ \\
\hline I don't know & 28 & $2.5(0-8)$ & $20.5(15-27)$ & $7(3-15)$ & $21(8-34)$ & $33.5(24-40)$ & $12(5-15)$ & $51(30-62)$ \\
\hline$P$-value & 450 & 0.945 & 0.626 & 0.014 & 0.263 & 0.760 & 0.196 & 0.736 \\
\hline
\end{tabular}

HBM Health Belief Model, CC Cervical Cancer

between these beliefs and socio-demographic characteristics. Our results showed that $26 \%$ of participants had undergone a Pap smear test, which is in agreement with data from other developing countries. The uptake of the Pap smear test was reported to be $23.8 \%$ in Kuwait [25], $21 \%$ in Jamaica [26], 21.9\% in Turkey [27], $15.7 \%$ in Nepal [28], and $12 \%$ in Ghana [29]. In contrast, the Pap smear test uptake rate has been reported to be much higher in developed countries, at 93\% in the USA [30], and $72 \%$ in the United Kingdom [31]. In fact, more than half of the participants in our study did not have any knowledge about the cervical cancer screening test. This lack of knowledge or incorrect information perceived by the participants could be the main reason for the low uptake rate of the Pap smear test, as has been shown in other studies [25, 28, 29, 32]. Hence, we recommend that all possible efforts should be made to increase awareness of the importance of the Pap smear test, and that the media should be recruited to help in this regard. A similar study conducted in Turkey also recommends involving the media in programs dedicated to improving cervical cancer awareness [27]. However, it is interesting to note that, in our study, the media was less preferred by women as a source of information, and more women sought such information from health professionals.

Currently, some of Saudi Arabia's major hospitals offer the HPV vaccine based on a doctor's prescription. Thus, primary healthcare physicians should provide more information about the HPV vaccine and should recommend timely vaccination to their patients [33]. The present study showed a low uptake of HPV vaccine in Saudi Arabia among women (1\%); this uptake rate was significantly lower than that reported from other countries such as the United Kingdom (range: 44.0 to 93.4\%) [34], USA (range: 56.1 to $60.4 \%$ ) [35], Malaysia (77.0\%) [36], and Egypt (19.9\%) [19]. This may be due to the lack of a national HPV vaccination program in Saudi Arabia. In a recent cohort study conducted in Saudi Arabia, it was reported that out of 400 screened cervical specimens, 67 specimens (17\%) were positive for HPV DNA. There were 291 Saudi women, only 47 out of them were positively tested for HPV. While there were 20 positive tests out of the 109 for the remaining non-Saudi women (Philippines, Jordanian, European, 
Table 3 Knowledge and practice of participants regarding the cervical screening test $(n=450)$

\begin{tabular}{lll}
\hline & Number & Percent \\
\hline Do you know about the Pap test & & \\
Yes & 219 & 48.7 \\
No & 231 & 51.3
\end{tabular}

If the answer to the previous question was "yes", please answer the following question $(n=219)$

The source of information for the Pap smear test

$\begin{array}{lll}\text { Health professional } & 131 & 59.8 \\ \text { Family } & 17 & 7.8 \\ \text { Media } & 52 & 23.7 \\ \text { Other (friends, neighbors, etc.) } & 19 & 8.7\end{array}$

The Pap smear test is the primary test used for cervical cancer screening

$\begin{array}{lll}\text { Yes } & 110 & 50.2\end{array}$

$\begin{array}{lll}\text { No } & 25 & 11.4\end{array}$

I don't know $\quad 84 \quad 38.4$

Cervical cancer is the most common cancer in women

$\begin{array}{lll}\text { Yes } & 63 & 28.8\end{array}$

$\begin{array}{lll}\text { No } & 66 & 30.1\end{array}$

I don't know $\quad 90 \quad 41.1$

Did you undergo a Pap test?(excluded single women $n=392$ )

Yes $101 \quad 26$

$\begin{array}{lll}\text { No } & 291 & 74\end{array}$

Appropriate age for screening for married women

$\begin{array}{lll}\text { I don't know } & 149 & 33.1 \\ 15-20 & 41 & 9.2 \\ 21-29 & 51 & 11.4 \\ 30-40 & 192 & 42.6 \\ 41-50 & 17 & 3.7 \\ \text { Mean } \pm \text { SD } & 31.8 \pm 7.8 & \\ \text { Range (Min. - Max.) } & 15.0-50 & \end{array}$

SD standard deviation, Min minimum, Max maximum

South Asian, Americans and Africans). Another study also from Saudi Arabia found that 31\% of participants were positive for HPV DNA [37]. Further studies are needed to measure the real prevalence of HPV at the national level; thus, there is a need for implementing HPV awareness campaigns and to promote HPV vaccination programs in Saudi Arabia [37].

In the present study, women perceived themselves to have a low susceptibility to cervical cancer and that this cancer is a moderately serious disease. Hence, this belief may have contributed to the low uptake of the screening test. This finding is in concordance with a systemic review of 12 studies, which reported that the Pap smear test uptake was directly associated with higher scores of susceptibilities, seriousness, and benefits, and was indirectly associated with perceived barriers to undergoing the test $[38,39]$. However, Saudi women in this study showed high scores for perceived benefits, motivation, and reported lower levels of perceived barriers to cervical cancer screening, which is in contrast with the findings of the previous systematic study. This apparent discrepancy may be attributed to the low awareness of the disease among the participating women, and because the screening test was offered only at tertiary care hospitals.

It is possible that a higher level of education and working status as seen in the present study were associated with better knowledge; these parameters were found to be statistically significant $(P>0.05)$ in our study. Along the same lines, a study conducted in the United Arab Emirates found a positive association between a high level of education or a "working" status and good knowledge about of cervical cancer [40].

However, women who had a low education level and a positive family history of cervical cancer believed that they were more susceptible to developing cervical cancer; the latter finding is in agreement with that reported by a Turkish study [27]. Another study found that women who have a positive family history of cancer are more likely to undergo a Pap smear test [41].

Further, more than one-third of women perceived the seriousness of the disease in the present study. Similarly, one-third of participants in a Vietnamese-American study also believed that cancer would threaten their relationship with their partner/husband and having cervical cancer would change their whole life. However, these beliefs did not translate into the action of undergoing a Pap smear test [42].

The present study showed that $27 \%$ of the participants perceived several barriers to undergoing a Pap smear test. Socio-cultural barriers included feeling embarrassed about having to undergo a gynecologic examination (40.5\%) and not having access to a female doctor (79\%). Participants may feel embarrassed about showing their private part/s to a physician during a physical examination, especially if the doctor is male. This finding is in line with a study conducted among Egyptian women (who shared similar Arabic and Islamic culture as Saudi women) which showed that $76.9 \%$ of women prefer a female doctor to perform the Pap smear procedure [19]. However, a study of Vietnamese-American women showed that women felt uncomfortable to undergo Pap smear screening performed by a male doctor (38.8\%) [42]. Modesty and embarrassment were reported frequently as barriers for cervical cancer screening programs among Arab Muslim women in the USA [43].

False interpretation of Islamic beliefs led to $42 \%$ of women to believe that "if cervical cancer development is part of my destiny, having a Pap smear test cannot prevent it"; however, the Islamic faith encourages Muslims 
Table 4 Human papilloma virus (HPV) vaccine uptake among study participants ( $n=450)$

\begin{tabular}{ll}
\hline Have you been vaccinated against HPV? & 4 \\
Yes & 424 \\
No & 22 \\
I don't no & 410 \\
If the answer to the previous question was "no," then what was the reason for not being vaccinated? & $29.2 \%$ \\
I don't know anything about the vaccine & $4.9 \%$ \\
Other (expensive, fear of infection as a result of this vaccination, and refusal of parents or husband) & 7 \\
No answer & $91.1 \%$ \\
Age at vaccination for HPV & 258 \\
I don't know & 13 \\
18years or less & $5.4 \%$ \\
19-26years & 58 \\
27 years and more & $1.6 \%$ \\
Mean \pm SD & 121 \\
Range (Min. - Max.) & $29.943 \pm 8.588$ \\
\hline
\end{tabular}

to perform self-care, seek treatment, and to provide health support [43]. It was narrated that the Prophet (PBUH): said: "Seek treatment, O slaves of Allah! For Allah does not create any disease but he also creates with it the cure, except for old age." [44].

Healthcare organizations play an important role in popularizing and administering the Pap smear test. This is reflected in our study, since $52 \%$ of participants did not know where to go for a Pap smear test; this finding is in agreement with that reported by a similar study conducted in Turkey. The investigators found that the Pap smear test uptake was four times lower if the women were not aware of where the test was offered than if they were aware of this information. Therefore, cervical cancer screening programs should provide information not only regarding the benefits and the procedure, but also provide adequate information of where it is offered [45].

Many studies have shown that financial concerns may act as barriers to undergoing a Pap smear test if the women have to pay for the test. More than half of the women in two other similar studies believed it was too expensive to have a Pap smear test; however, only 21\% of participants in our study considered the cost to be a barrier. This finding may be explained by the fact that the majority of women in our study had free access to hospitals or had medical insurance coverage, and that the income of the Saudi population is relatively high $[42,45]$.

The fear of pain involved in the Pap smear test procedure may prevent some women from undergoing the test. Therefore, explaining the procedure may reduce anxiety and improve the uptake in women. Fortunately, in our study, the percentage of Saudi women who had experienced pain during the test (among those who had undergone a Pap smear test) was low, at $28.7 \%$; this figure is lower than that reported by a similar study conducted in Turkey (59\%). The Turkish study found that fear of pain among women made them four times less likely to undergo a Pap smear test [45].

There are several limitations to this study. The women who participated in the study were selected from Riyadh city, and were highly educated. Therefore, the results may not be generalizable to all Saudi women. This cross-sectional study was conducted using a self-administered questionnaire, and recall bias cannot be ruled out due to such a study design.

Table 5 Comparative cervical cancer health belief model parameter data of participants as per health institutions $(n=450)$

\begin{tabular}{|c|c|c|c|c|}
\hline & $\begin{array}{l}\text { Health care centers } \\
(n=150)\end{array}$ & $\begin{array}{l}\text { KKUH } \\
(n=150) \\
\end{array}$ & $\begin{array}{l}\mathrm{MOH} \\
(n=150)\end{array}$ & $P$-value \\
\hline Susceptibility (to cervical cancer) & $8.0(3.0)(3.0-13.0)$ & $7.0(3.0)(3.0-15)$ & $7.5(3.0)(3.0-15.0)$ & 0.452 \\
\hline Seriousness (of cervical cancer) & $21.0(8.25)(7.0-33.0)$ & $21.0(8.25)(7.0-35.0)$ & $21.0(7.0)(7.0-35.0)$ & 0.986 \\
\hline Benefits (of the Pap smear test) & $34.0(6.0)(8.0-40.0)$ & $35.0(6.0)(20.0-40.0)$ & $36.0(6.0)(8.0-40.0)$ & 0.022 \\
\hline Health Motivation & $12.0(3.25)(3.0-15.0)$ & $12.0(4.0)(3.0-15.0)$ & $12.0(3.25)(3.0-15.0)$ & 0.280 \\
\hline Barriers (to undergoing a Pap smear test) & $52.5(11.0)(18.0-81.0)$ & $52.0(12.0)(27.0-80.0)$ & $51.0(13.0)(18.0-85.0)$ & 0.649 \\
\hline
\end{tabular}

*Kruskal-Wallis test Median (Interquartile range) (minimum - maximum)

KKUH King Khaled University Hospitals, $\mathrm{MOH}$ Ministry of Health hospitals 
Table 6 Health belief model scores of participants (single participants excluded: $N=392$ )

\begin{tabular}{|c|c|c|c|}
\hline Variables & Agree & Neutral & Disagree \\
\hline \multicolumn{4}{|l|}{ Susceptibility } \\
\hline It is likely that I will get cervical cancer in the future & 82 & 169 & 141 \\
\hline My chances of getting cervical cancer in the next few years are high & 37 & 143 & 212 \\
\hline I feel I will get cervical cancer some time during my life & 21 & 128 & 243 \\
\hline Average score & 46.6 & 146.6 & 198.6 \\
\hline$\%$ & 11.9 & 37.4 & 50.6 \\
\hline \multicolumn{4}{|l|}{ Seriousness } \\
\hline The thought of cervical cancer scares me & 173 & 90 & 129 \\
\hline When I think about cervical cancer, my heart beats faster & 137 & 99 & 156 \\
\hline I am afraid to think about cervical cancer & 205 & 69 & 118 \\
\hline Problems I would experience with cervical cancer would last a long time & 140 & 129 & 123 \\
\hline Cervical cancer would threaten a relationship with my husband & 176 & 103 & 113 \\
\hline If I had cervical cancer my whole life would change & 175 & 101 & 116 \\
\hline If I developed cervical cancer, I would not live longer than 5 years & 50 & 143 & 199 \\
\hline Average score & 150.8 & 104.8 & 136.2 \\
\hline$\%$ & 38.4 & 26.7 & 34.7 \\
\hline \multicolumn{4}{|l|}{ Benefits } \\
\hline I want to discover health problems early & 339 & 36 & 17 \\
\hline Maintaining good health is extremely important to me & 344 & 31 & 17 \\
\hline I look for new information to improve my health & 355 & 27 & 10 \\
\hline I feel it is important to carry out activities which will improve my health & 352 & 31 & 9 \\
\hline Having regular Pap smear tests will help to find changes to the cervix, before they turn into cancer & 325 & 54 & 13 \\
\hline If cervical cancer was found at a regular Pap smear test its treatment would not be so bad & 283 & 63 & 46 \\
\hline I think that having a regular Pap smear test is the best way for cervical cancer to be diagnosed early & 325 & 51 & 16 \\
\hline Having regular Pap smear tests will decrease my chances of dying from cervical cancer & 276 & 77 & 39 \\
\hline Average score & 325 & 46 & 20.8 \\
\hline$\%$ & 82.8 & 11.7 & 5.3 \\
\hline \multicolumn{4}{|l|}{ Motivation } \\
\hline I eat well-balanced meals for my health & 310 & 64 & 18 \\
\hline I exercise at least 3 times a week for my health & 263 & 91 & 38 \\
\hline I have regular health check-ups even when I am not sick & 240 & 93 & 59 \\
\hline Average score & 271 & 82.6 & 38.3 \\
\hline$\%$ & 69.1 & 21.1 & 9.7 \\
\hline \multicolumn{4}{|l|}{ Barriers } \\
\hline I am afraid to have a Pap smear test for fear of a bad result & 88 & 98 & 206 \\
\hline I am afraid to have a Pap smear test because I don't know what will happen & 96 & 100 & 196 \\
\hline I don't know where to go for a Pap smear test & 203 & 73 & 116 \\
\hline I would be ashamed to lie on a gynecologic examination table & 159 & 61 & 172 \\
\hline Undergoing a Pap smear test takes too much time & 46 & 192 & 154 \\
\hline Undergoing a Pap smear test is too painful & 83 & 188 & 121 \\
\hline Health professionals performing Pap smear tests are rude to women & 48 & 166 & 178 \\
\hline I neglect or cannot remember to have a Pap smear test regularly & 148 & 142 & 102 \\
\hline I have other problems in my life which are more important than having a Pap smear test & 72 & 106 & 214 \\
\hline I am too old to have a Pap smear test regularly & 33 & 87 & 272 \\
\hline
\end{tabular}


Table 6 Health belief model scores of participants (single participants excluded: $N=392$ ) (Continued)

\begin{tabular}{|c|c|c|c|}
\hline Variables & Agree & Neutral & Disagree \\
\hline There is no health center close to my house to have a Pap smear test & 147 & 115 & 130 \\
\hline If there is cervical cancer development in my destiny, having a Pap smear test cannot prevent it & 166 & 88 & 138 \\
\hline I prefer that a female doctor conducts a Pap smear test & 310 & 58 & 24 \\
\hline I will never have a Pap smear test if I have to pay for it & 85 & 91 & 216 \\
\hline I do not have time to get a Pap smear test & 60 & 111 & 221 \\
\hline The Pap smear test may move the intrauterine device & 35 & 234 & 123 \\
\hline My husband does not want me to get a Pap smear test & 29 & 128 & 235 \\
\hline It Is difficult to get an appointment for a Pap smear test & 125 & 123 & 144 \\
\hline Average score & 107.4 & 120.1 & 164.5 \\
\hline$\%$ & 27.4 & 30.6 & 41.9 \\
\hline
\end{tabular}

\section{Conclusions}

This study showed a high incidence of perceived benefits and motivation, and low incidence of perceived barriers among women with regard to cervical cancer screening. However, the data also showed that these perceived benefits and motivation did not translate to practice, and only a small percentage of women underwent the screening test. Furthermore, there is no current national program for cervical cancer screening in Saudi Arabia. Following the implementation of the new Saudi vision 2030 and health system reform, which emphasizes on the importance of prevention, we recommend launching a national cervical cancer screening program, which is available and accessible to all women at primary health care centers and hospitals. Such a program should be designed to improve awareness, to overcome any perceived barriers to screening, and hopefully to increase the uptake of screening. These measures may promote earlier detection of cancer among women and contribute to lowering the mortality rates associated with cervical cancer.

\section{Abbreviations}

HBM: Health belief model; HPV: Human papillomavirus; USA: United States of America

\section{Acknowledgements \\ The researchers would like to thank the hospitals and primary centers for allowing them to conduct the study. The authors are grateful to the Deanship of Scientific Reserch at King Saud University for supporting through Vice Deanship of Scientific Reserch Chairs. Also, thanks to Dr. Abdullah Alkahiel for his help. Special thanks also to the women who participated, for their time, honesty, and effort.}

\section{Availability of data and materials}

The data sets used and analyzed during the current study are available from the corresponding author on reasonable request.

\section{Authors' contributions}

AA collected, interpreted the data and drafted the article, SA review study design and revised the manuscript. Both authors read and approved the final manuscript. SA data entery and writing the result section.
Ethics approval and consent to participate

The institutional review board of the College of Medicine, King Saud University, approved the project proposal prior to the initiation of the study.

\section{Consent for publication}

Not applicable.

\section{Competing interests}

The authors declare that they have no competing interests.

\section{Publisher's Note}

Springer Nature remains neutral with regard to jurisdictional claims in published maps and institutional affiliations.

Received: 8 August 2018 Accepted: 12 December 2018

Published online: 08 January 2019

\section{References}

1. Ferlay J, Soerjomataram I, Dikshit R, Eser S, Mathers C, Rebelo M, et al. Cancer incidence and mortality worldwide: sources, methods and major patterns in GLOBOCAN 2012. Int J Cancer. 2015;136:E359-86.

2. Catarino $R$, Petignat $P$, Dongui $G$, Vassilakos $P$. Cervical cancer screening in developing countries at a crossroad: emerging technologies and policy choices. World J Clin Oncol. 2015;6:281-90.

3. Ferdous J, Khatun S, Ferdous NE, Sharmin F, Akhter L, Keya KA. Attitude and practice of cervical cancer screening among the female doctors of Bangabandhu sheikh Mujib Medical University. Bangladesh Med J. 2016; 45:66-71.

4. Al-Zahrani DAS. Cancer Incidence Report Saudi Arabia. 2014. https://nhic. gov.sa/eServices/Documents/2014.pdf. Accessed 7 Aug 2018.

5. Al-Mandeel HM, Sagr E, Sait K, Latifah HM, Al-Obaid A, Al-Badawi IA, et al. Clinical practice guidelines on the screening and treatment of precancerous lesions for cervical cancer prevention in Saudi Arabia. Ann Saudi Med. 2016; 36:313-20.

6. Manji M. Cervical cancer screening program in Saudi Arabia: action is overdue. Ann Saudi Med. 2000;20:355-7.

7. Al-Naggar RA, Low W, Isa ZM. Knowledge and barriers towards cervical cancer screening among young women in Malaysia. Asian Pac J Cancer Prev. 2010;11:867-73.

8. Markowitz LE, Dunne EF, Saraiya M, Chesson HW, Curtis CR, Gee J, et al. Human papillomavirus vaccination: recommendations of the advisory committee on immunization practices (ACIP). MMWR Recomm Rep. 2014:63:1-30.

9. Petrosky E, Bocchini JJ, Hariri S, Chesson H, Curtis CR, Saraiya M, et al. Use of 9-valent human papillomavirus (HPV) vaccine: updated HPV vaccination recommendations of the advisory committee on immunization practices. MMWR Morb Mortal Wkly Rep. 2015;64:300-4.

10. Alali A, Salem M, Elmahdi H, Alkubaisi N, Alwahedi Z, Taher M, et al. Knowledge, attitudes and practices regarding cervical cancer screening among female health care workers in primary healthcare in Qatar. Middle East J Fam Med. 2016;14:4-15. 
11. Cancer ICoESoC. Comparison of risk factors for invasive squamous cell carcinoma and adenocarcinoma of the cervix: collaborative reanalysis of individual data on 8,097 women with squamous cell carcinoma and 1,374 women with adenocarcinoma from 12 epidemiological studies. Int J Cancer. 2007;120:885-91.

12. Fotedar $\mathrm{V}$, Fotedar $\mathrm{S}$, Thakur $\mathrm{P}$, Sharma M, Sharma A. Awareness about cervical cancers among health workers in Shimla district, Himachal Pradesh, India. Int J Reprod Contrac Obstet Gynecol. 2017;6:4419-23.

13. Canfell K, Sitas F, Beral V. Cervical cancer in Australia and the United Kingdom: comparison of screening policy and uptake, and cancer incidence and mortality. Med J Aust. 2006;185:482-6.

14. Kurman RJ, Henson DE, Herbst AL, Noller KL, Schiffman MH. Interim guidelines for management of abnormal cervical cytology. The 1992 National Cancer Institute workshop. JAMA. 1994;271:1866-9.

15. Saslow D, Castle PE, Cox JT, Davey DD, Einstein MH, Ferris DG, et al. American Cancer Society guideline for human papillomavirus (HPV) vaccine use to prevent cervical cancer and its precursors. CA Cancer J Clin. 2007;57:7-28,

16. Mutyaba T, Mmiro FA, Weiderpass E. Knowledge, attitudes and practices on cervical cancer screening among the medical workers of Mulago hospital, Uganda. BMC Med Educ. 2006;6:13.

17. Moyer VA. Screening for cervical cancer: U.S. preventive services task force recommendation statement. Ann Intern Med. 2012;156:880-91.

18. Organization WH, Health WHOR, Diseases WHOC, Promotion $H$ Comprehensive cervical cancer control: a guide to essential practice, Second edition edn. Geneva 27: World Health Organization; 2006.

19. Yakout SM, Moawed S, Gemeay EM. Cervical Cancer and screening test (PAP test): knowledge and beliefs of Egyptian women. Am J Nurs Sci. 2016;5:17584.

20. Abolfotouh MA, BaniMustafa AA, Mahfouz AA, Al-Assiri MH, Al-Juhani AF, Alaskar AS. Using the health belief model to predict breast self examination among Saudi women. BMC Public Health. 2015;15:1163.

21. Darvishpour A, Vajari SM, Noroozi S. Can health belief model predict breast cancer screening behaviors? Open Access Maced J Med Sci. 2018;6:949-53.

22. Salem MR, Amin T, Alhulaybi AA, Althafar AS, Abdelhai RA. Perceived risk of cervical cancer and barriers to screening among secondary school female teachers in Al Hassa, Saudi Arabia. Asian Pac J Cancer Prev. 2017;18:969-79.

23. Guvenc G, Akyuz A, Açikel CH. Health belief model scale for cervical cancer and pap smear test: psychometric testing. J Adv Nurs. 2011;67:428-37.

24. Beaton DE, Bombardier C, Guillemin F, Ferraz MB. Guidelines for the process of cross-cultural adaptation of self-report measures. Spine. 2000;25:3186-91.

25. Al Sairafi M, Mohamed FA. Knowledge, attitudes, and practice related to cervical cancer screening among Kuwaiti women. Med Princ Pract. 2009;18: 35-42.

26. Bourne PA, Charles CA, Francis CG, South-Bourne N, Peters R. Perception, attitude and practices of women towards pelvic examination and pap smear in Jamaica. N Am J Med Sci. 2010;2:478-86.

27. Isik G. Cervical cancer and pap smear test health beliefs and healthpromoting lifestyle of women in Turkey. Int J Caring Sci. 2016;9:630-9.

28. Ranabhat S, Tiwari M, Dhungana G, Shrestha R. Association of knowledge, attitude and demographic variables with cervical pap smear practice in Nepal. Asian Pac J Cancer Prev. 2014;15:8905-10.

29. Abotchie PN, Shokar NK. Cervical cancer screening among college students in Ghana: knowledge and health beliefs. Int J Gynecol Cancer. 2009:19:412-6.

30. Sirovich BE, Welch HG. The frequency of pap smear screening in the United States. J Gen Intern Med. 2004;19:243-50.

31. Screening \& Immunisations Team ND. Cervical screening Programme. 2017. https://files.digital.nhs.uk/pdf/t/b/cervical_bulletin_report_2016-17 - final. pdf. Accessed 8 July 2018.

32. Jia Y, Li S, Yang R, Zhou H, Xiang Q, Hu T, et al. Knowledge about cervical cancer and barriers of screening program among women in Wufeng County, a high-incidence region of cervical cancer in China. PLoS One. 2013;8:e67005

33. Alsbeih G. HPV infection in cervical and other cancers in Saudi Arabia: implication for prevention and vaccination. Front Oncol. 2014;4:65.

34. Public Health England. Human Papillomavirus (HPV) vaccination coverage in adolescent females in England: 2016. https://assets.publishing.service.gov.uk government/uploads/system/uploads/attachment_data/file/666087/HPV_ vaccination coverage in adolescent females_in_England_2016 to 2017. pdf. Accessed 6 Aug 2018.

35. Walker TY, Elam-Evans LD, Singleton JA, Yankey D, Markowitz LE, Fredua B, et al. National, regional, state, and selected local area vaccination coverage among adolescents aged 13-17 years-United States, 2016. MMWR Morb Mortal Wkly Rep. 2017:66:874-82.

36. Al-Naggar RA, Bobryshev YV, Al-Jashamy K, Al-Musli M. Practice of HPV vaccine and associated factors among school girls in Melaka, Malaysia. Asian Pac J Cancer Prev. 2012;13:3835-40

37. Alhamlan FS, Khayat HH, Ramisetty-Mikler S, Al-Muammar TA, Tulbah AM, Al-Badawi IA, et al. Sociodemographic characteristics and sexual behavior as risk factors for human papillomavirus infection in Saudi Arabia. Int J Infect Dis. 2016:46:94-9.

38. Bayu H, Berhe Y, Mulat A, Alemu A. Cervical cancer screening service uptake and associated factors among age eligible women in Mekelle zone, northern Ethiopia, 2015: a community based study using health belief model. PLoS One. 2016;11:e0149908.

39. Tanner-Smith EE, Brown TN. Evaluating the health belief model: a critical review of studies predicting mammographic and pap screening. Soc Theory Health. 2010;8:95-125.

40. Metwali Z, Al Kindi F, Shanbleh S, Al Akshar S, Sarhan F. Evaluating awareness and screening of cervical cancer among women in Sharjah, United Arab Emirates. IOSR J Pharm. 2015;5:57-64.

41. Oran NT, Can HO, Senuzun F, Aylaz RD. Health promotion lifestyle and cancer screening behavior: a survey among academician women. Asian Pac J Cancer Prev. 2008:9:515-8.

42. Ma GX, Gao W, Fang CY, Tan Y, Feng Z, Ge S, et al. Health beliefs associated with cervical cancer screening among Vietnamese Americans. J Women's Health. 2013;22:276-88.

43. Salman KF. Health beliefs and practices related to cancer screening among Arab Muslim women in an urban community. Health Care Women Int. 2012;33:45-74.

44. Majah I. Chapters on Medicine. Vol. 4, Book 31, Hadith 3436. https://sunnah. com/urn/1335630. Accessed 15 July 2018

45. Esin MN, Bulduk S, Ardic A. Beliefs about cervical cancer screening among Turkish married women. J Cancer Educ. 2011;26:510-5.

\section{Ready to submit your research? Choose BMC and benefit from:}

- fast, convenient online submission

- thorough peer review by experienced researchers in your field

- rapid publication on acceptance

- support for research data, including large and complex data types

- gold Open Access which fosters wider collaboration and increased citations

- maximum visibility for your research: over $100 \mathrm{M}$ website views per year

At BMC, research is always in progress.

Learn more biomedcentral.com/submissions 